\title{
The debate about wheelchair spaces on buses goes 'round and round': access to public transport for people with disabilities as a human right
}

\author{
Abigall Pearson
}

Keele University ${ }^{1}$

\begin{abstract}
This article examines the cases bought by Paulley concerning access to buses for wheelchair users when the wheelchair space is occupied by a buggy. It argues that the conclusion by the Supreme Court was unsatisfactory and a missed opportunity for a public statement about the rights of people with disabilities. It argues that reasonable adjustment is a problematic concept and fails to address the competing needs of social groups in terms of accessibility. This is compounded by traditional distinctions between disability and impairment and a failure to consider disability access in the context of human rights despite the ratification of the UN Convention on the Rights of Persons with Disabilities.
\end{abstract}

Keywords: Paulley; CRPD; accessibility; reasonable adjustment; wheelchair space; disability; rights; access to transport.

he 'Wheels on the Bus'2 is a sweet nursery rhyme sung by and to children to keep
them amused on a journey. However, through adult eyes, it can be a neat encapsulation of our society and, more specifically, a comment about social representation and participation. Think about it: we've got the mums, we've got the dads and we've got the kids, but what about everybody else? Increasingly, the absence of everybody else and their co-existence with the mums, dads and kids on public transport is becoming an unavoidable question that needs to be answered. The recent court cases, brought by Mr Doug Paulley, concerning the balance between access to public buses for wheelchair users and parents with buggies, have revealed several deficiencies in the legal framework protecting and promoting the equal social, economic and cultural rights of persons with disabilities. Discussions around this issue, both in and out of the courtroom, give an insight into the changes and discourses critical to future legislative developments ensuring substantively equal access for all people with disabilities.

This article will explore these issues by first giving a brief overview of the developments of the cases from the County Court at Leeds, ${ }^{3}$ to the Court of Appeal ${ }^{4}$ and

1 With many thanks to Professor Anthony Bradney, Dr Eliza Varney and Dr Michael Fay for their feedback and encouragement during the pre-submission phase for this article.

2 'The Wheels on the Bus' by Verna Hills, Boston Massachusetts. See American Childhood, vol 25 (Milton Bradley 1939).

3 Paulley v First Group plc [2013] Leeds County Court Case 2YL85558.

4 First Group ple v Paulley [2014] COA EWCA Civ 1573. 
then to the Supreme Court. ${ }^{5}$ Then, the article will move on to discuss the key issues and arguments that were common to all the cases to highlight what they reveal about the strengths and weaknesses of the legislative framework concerning the rights of people with disabilities and societal attitudes. At the same time, it will consider how to address any weaknesses and to animate the legislative framework to bridge the gap between its intention and practice. Lastly, conclusions will be drawn about the steps needed to deliver equality in practice.

\section{Legislative context}

The right of wheelchair users to access public service vehicles (such as buses and coaches) whilst remaining in their wheelchairs was first protected by Part $\mathrm{V}$ of the Disability Discrimination Act (DDA) $1995^{6}$ after years of direct protest by people with disabilities. ${ }^{7}$ In 2010 the provisions of the DDA 1995 were absorbed into the Equality Act. ${ }^{8}$ However, no such legislation exists for parents without disabilities with buggies.

\section{The cases}

\section{The LeEds County Court CASE}

Mr Paulley brought a claim of unlawful discrimination against First Group plc. The case focused on the need to clarify the firm's policy on the position of wheelchair users using the bus when the designated space is occupied by other passengers.

On 24 February 2012, when attempting to board a bus from Wetherby to Leeds, Mr Paulley submitted that he was unable to travel on the bus as the wheelchair space contained a pushchair with a sleeping child. The driver, in line with First Group plc's policy, asked the mother to move (by folding her pushchair) so that Mr Paulley could use the wheelchair space, but she refused. The driver felt that he could not compel her to move, so informed Mr Paulley that he would be unable to travel. Mr Paulley asked whether it would be possible for him to fold his wheelchair, store it elsewhere on the bus and sit in a passenger seat. However, the driver refused because it could create potential risk as the wheelchair could not be restrained when folded. Consequently, Mr Paulley took a later bus and missed his train.?

It was decided by the court that First Group could be said to have a provision, criterion or practice (PCP) which placed Mr Paulley at a disadvantage in relation to other passengers and that the proposed adjustment of a 'first-come, first-served' access to the space made by the company was not effective. Mr Paulley was awarded damages of $f, 5500$ for injury to feelings ${ }^{10}$ and no injunctive order was made for six months to give First Group time to address the issues raised. ${ }^{11}$

5 First Group plc (Respondent) v Paulley (Appellant) [2017] UKSC 4.

6 Disability Discrimination Act 1995.

7 Damon Rose, 'When Disabled People Took to the Streets to Change the Law' BBC News (7 November 2015) $<$ www.bbc.co.uk/news/disability-34732084>.

8 Equality Act 2010.

9 Paulley v First Group plc [2013] Leeds County Court Case 2YL85558, [3].

10 Ibid [24].

11 Ibid [25]. 


\section{The Court of APPEAL CASE}

First Group was granted an appeal of the initial decision. The focus was on whether a bus company should have a policy to compel other abled-bodied passengers to vacate the wheelchair space, if it is required by a wheelchair user. ${ }^{12}$

The first issue to be considered was whether the PCP placed disabled people at a substantial disadvantage. Here, Lewison LJ drew attention to the fact that it was not whether a disabled person is at a substantial disadvantage to a non-disabled person, but whether the PCP has caused the disadvantage. ${ }^{13}$ Lewison LJ could not form the necessary causative link between the PCP and the delay that Mr Paulley suffered. He argued that had another wheelchair user been occupying the space, and there had been free seats on board, Mr Paulley would still have been unable to travel because the Public Service Vehicle Accessibility Regulations 2000 prevent a wheelchair user from travelling outside of the designated wheelchair space. ${ }^{14}$

The next point to be considered was whether the PCP caused a substantial disadvantage. Whilst Lewison LJ was not prepared to overturn the County Court judge's assessment of the disadvantage as substantial, as there was no suggestion that the delay Mr Paulley suffered was atypical, he did question the extent to which any delay could constitute a substantial disadvantage, as the bus ran every 20 minutes. ${ }^{15}$ However, this ruling could make delays even more likely, if the space is now more likely to be filled with a buggy because parents may be more reluctant to move than they were before the ruling.

The main difference between the Court of Appeal case and the County Court case was whether or not the 'first-come, first-served' element of access to the wheelchair space constituted a PCP, and whether or not it placed wheelchair users at a substantial disadvantage. ${ }^{16}$ Lewison LJ was of the opinion that it did constitute a PCP, but that the reasoning and definition arrived at by the County Court judge was incorrect. Lewison LJ expressed concerns about the description of the 'first-come, first-served' convention as a PCP because it did not apply to everyone. If a parent with a buggy wanted to use the wheelchair space, non-disabled passengers who were using the space would not be asked to vacate it. ${ }^{17}$ Consequently, Lewison LJ argued that the PCP incorporated a reasonable adjustment and a step to comply with the duty. ${ }^{18} \mathrm{He}$ referred to Finnigan v Chief Constable of Northumbria Police, ${ }^{19}$ which stated that a PCP is the policy before a reasonable adjustment is implemented.

The court decided that to rule that bus companies should have a policy to compel other people to vacate the wheelchair space by leaving the bus would be unreasonable for several reasons. Firstly, that the bus driver would not have the power to remove a person from the bus physically without opening him or herself to potential battery charges. ${ }^{20}$ Arguments were also made that parents with an ill or disabled child, who needed to keep a hospital appointment, or a parent with a disability might not be able to take the child

12 First Group plc v Paulley [2014] COA EWCA Civ 1573, [1].

13 Ibid [36].

14 Public Service Vehicle Accessibility Regulations 2000, s 12(4).

15 First Group plc v Paulley [2014] COA EWCA Civ 1573, [39].

16 Ibid [41].

17 Ibid [34].

18 Ibid [32].

19 Finnigan v Chief Constable of Nortbumbria Police [2013] EWCA Civ 1191; [2014] 1 WLR 445, [29].

20 First Group plc v Paulley [2014] COA EWCA Civ 1573, [50] 
out of the buggy; or a person with another impairment might require use of the space. ${ }^{21}$ Moreover, it was argued that a driver would not be able to make an accurate assessment of whose needs were greater, due to a lack of training. ${ }^{22}$ Lastly, it was considered that for particular groups, such as persons with a visual impairment or a mother stranded with a baby, being removed from a bus might cause more disadvantage to them than to a wheelchair user who had to wait, due to differences in vulnerability. ${ }^{23}$

\section{THE SUPREME COURT CASE}

The Supreme Court case was heard on 15 June 2016. The outcome of the case was a partial victory for Mr Paulley and a partial resolution of the issues put before the court. It was decided that the damages awarded by the County Court would not be restored and, whilst there was no requirement for First Group to have a policy which compelled people to leave the bus or the wheelchair space when it was required by a wheelchair user, the court found that the company had a duty to do more than simply ask and then accept a refusal. It was argued that additional measures could include stopping the bus for a short period to pressurise the intransigent passenger into moving.

\section{Taking the scenic route to equality?}

There are several commonalities between the reasoning in the cases which highlighted and compounded existing weaknesses in the legal framework relating to the rights of persons with disabilities and social attitudes. These will be explored in the following sections.

\section{THE UN CRPD: RUNNING FOR THE BUS?}

It would have been valuable for the Supreme Court to consider disability more widely and in relation to human rights generally. Under the UN Convention on the Rights of Persons with Disabilities (CRPD), which was ratified by the UK in 2009, domestic laws must be consistent with it by expressing and reaffirming the human rights of persons with disabilities to ensure full equality under the law. ${ }^{24}$ The absence of the CRPD from the discussions is disappointing, because it has the effect of transforming the convention into an Excalibur figure, with the potential for great power, but only when it is released. Until the courts and the UK government realise its power in practice, then its potential for meaningful change for people with disabilities will be limited to rhetoric rather than action.

Article 1 of the Convention offers wide-ranging guidance on the concept of disability, which encompasses long-term physical, mental, intellectual or sensory impairments. It also makes specific reference to the origin of disability in the interaction between impairment and society leading to social exclusion. Article 7 of the CRPD makes specific reference to the rights of children with disabilities, which would mean that a nonimpaired parent with a disabled child would have the right to access the wheelchair space if needed. If the judges had considered disability in terms of the CRPD definition, then an inclusive stance could have been taken to stop any person without impairment from preventing a person with an impairment from accessing the wheelchair space when requested to do so by the driver, regardless of whether the person was a wheelchair user

21 Ibid [52].

22 Ibid [53].

23 Ibid [54]-[55].

24 CRPD and Optional Protocol (2006), Article 1. 
or not. This is because the term non-disabled, non-wheelchair user causes some difficulty when considered in the context of the social model distinction between disability and impairment. ${ }^{25}$ If disability is the result of the interaction between the impairment, or the biological aspect of disability and societal barriers, ${ }^{26}$ such as a lack of accessible seating, then it may be possible to argue that a person with an impairment may find themselves to be disabled as a result of having to leave the accessible part of the bus so that another person can use it to remove their own disability. Therefore, I would argue that distinction should be drawn between passengers based on impairment rather than disability status.

It may seem strange to use what appears to be a medical model idea about the primacy of impairment over disability when discussing social access in relation to disability. In the social model, people are born with or acquire an impairment which does not necessarily disable them until they come into contact with societal, attitudinal or architectural barriers. ${ }^{27}$ Conversely, the medical or individualist approach to disability is that it is the impairment, or the pathology of the individual with that impairment, which causes the disadvantage and disability that they experience, rather than any other external factors. This way of thinking often seeks to 'cure' the individual or to provide devices which lessen the overall impact of the impairment upon the individual's life. ${ }^{28}$ However, in such a context, the notion of disability is too inclusive because the focus on access to society may also be an issue for non-impaired parents with non-impaired children who may find it difficult to access certain public spaces when using baby apparatus. However, in the situation raised by Paulley, the focus on biology without choice, which is neatly encompassed by the notion of impairment, is important to emphasise. In these particular cases, it is the choice element that matters. Based on the restrictions in the Public Service Vehicle Regulations 2000, wheelchair users can only access the one space because they are not permitted, even if possible, to fold their wheelchairs and transfer on to a seat. There is no such restriction for parents with buggies, nor are they confined to using one form of transporting their babies; for example, they could choose to use a sling or backpack. This is a perfect example of what Shakespeare has termed 'interactionism' in relation to disability and impairment. In conceptual terms, Shakespeare considers the effects of maintaining the traditional clear-cut distinction between social-model and medical-model thinking on disability. ${ }^{29}$ Shakespeare argues that rather than sticking to these two diametrically opposed models, which have been traditionally favoured within British disability studies, it is possible to maintain a social-model sense of thinking about disability by looking at a number of the social-interactionalist models that exist. For example, he highlights some of the earlier works of Paul Hunt and UPIAS, which consider that disability arises from several factors and that no one factor should be treated in isolation from another. ${ }^{30}$ Shakespeare argues that these more liberalised ideas have become ossified and have eclipsed the other social-model approaches to disability in terms of popularity. He comments that no writers have directly aligned themselves to the medical model, rather, that the distinction came when no differentiation was made between impairment and disability. Shakespeare stresses that seminal texts, such as

25 C Barnes and G Mercer, 'Chapter 1', in C Barnes and G Mercer (eds), Implementing the Social Model of Disability: Theory and Research (Disability Press 2004) 3.

26 Ibid.

27 Ibid 15-19.

28 Ibid 9-10.

29 T Shakespeare, Disability Rights and Wrongs (Routledge 2006).

30 Ibid 12-13. 
Michael Oliver's 1990 Politics of Disablement, used personal tragedy theory and social oppression theory rather than the medical and social models. ${ }^{31} \mathrm{He}$ argues that this labelling results in an approach that regards disability as more than the dominance of doctors or diagnosis. ${ }^{32}$ For Oliver, it is an approach that sites disability within the individual, stemming from functional limitations or psychological losses, rather than seeing it as originating from difficulties interacting with society and the resulting oppression. ${ }^{33}$

Section 6(1) of the Equality Act 2010,34 which defines 'disability', supports the argument of ensuring access to public transport based on impairment, rather than disability, because, it states:

A person $(\mathrm{P})$ has a disability if $\mathrm{P}$ has a physical or mental impairment, and the impairment has a substantial and long-term adverse effect on P's ability to carry out normal day-to-day activities.

Being unable to use public transport due to the lack of an accessible space would be a constriction of day-to-day activity and this would not be limited solely to wheelchair users, but anyone else who needed to use the designated space as the result of an impairment which prevented them from accessing standard seats, such as needing to use a walking frame. However, despite interactionist approaches to disability, this definition is problematic in terms of human rights protection for people with disabilities at the domestic level because, while it uses the word 'disability', it focuses entirely on impairment within the individual, without considering the role of society and social structures. This serves to highlight that the Equality Act 2010 does not give any consideration to access rights for people with disabilities in terms of wider human rights because this misconception of impairment as 'disability' fails to acknowledge the dignity and autonomy of people with disabilities. Section 6 focuses on deficit and deviation from what is 'normal', rather than the worth of people with disabilities and their contributions to society, providing they can access it. Failure to consider factors outside of impairment renders s 6 different from interactionism because it does not permit people with disabilities to embrace either disability or impairment, depending on circumstance. Rather, it can be said that s 6 occupies a confusing hinterland, as disability is used as a label for impairment, and so is rendered meaningless.

There is scope within the CRPD, as I have argued elsewhere, to suggest that access to transport for disabled people constitutes part of the key human rights: respect for dignity and autonomy. ${ }^{35}$ Traditional understandings of dignity present difficulties in relation to disability rights because they are predicated on independence ${ }^{36}$ which can be a difficult threshold for some people with disabilities to meet, as they will never be able to achieve traditional independence. ${ }^{37}$ Quinn proposes a new understanding of autonomy that is not

31 Ibid 15.

32 Ibid.

33 Ibid 14-15.

34 Equality Act 2010

35 Abigail Pearson, 'What's Worth Got to Do with It? Language and the Socio-legal Advancement of Disability Rights and Equality' (2014) 20(3) Web JCLI.

36 Abigail Pearson, 'A Comparative Study of "Reasonable Adjustment" and "Undue Burden" Provisions for People with Disabilities Accessing Public Transport Services under European Union Law’ (Keele University September 2014) 15.

37 'Free from Outside Control; Not Subject to Another's Authority', A Stevenson (ed), Oxford Dictionary of English (3rd edn, Oxford University Press 2010). 
dependent on narrow definitions of independence, which may have traditionally excluded disabled people, depending on their particular impairment. ${ }^{38}$ This is an important restatement to make: Quinn proposes that all people, regardless of impairment, are supported in their decision-making process as they are influenced by the needs of others around them. ${ }^{39}$ Full understanding of these needs and contexts can only be gained if people can participate in their communities. ${ }^{40}$ Quinn's argument that autonomy within the CRPD means the ability to participate equally within society and to contribute makes the right to transportation an important factor in the autonomy of people with disabilities. ${ }^{41}$ Autonomy is a foundational concept of dignity, which is an inviolable right. Therefore, if people with disabilities are denied their right to full autonomy because of states' failures to make transportation accessible, it can be argued that they are also being denied their inviolable right to dignity. Consequently, access to transportation for people with disabilities could be viewed as a fundamental human right, meaning that the higher threshold of effectiveness should always be applied. ${ }^{42}$

Accessibility is an independent right under Article 9 of the CRPD. ${ }^{43}$ Effective and inclusive access to transport is central to achieving all the wider rights. Despite this, legislators maintain an economic rather than a rights-based approach, indicated by the presence of 'reasonable adjustment' and 'undue burden' 44 defences to limit the cost of access provision measures on service providers. Without effective and equal access to transport, people with disabilities cannot access education, ${ }^{45}$ health, ${ }^{46}$ social, political and cultural activities ${ }^{47}$ to fully enjoy the rights automatically conferred on them by the CRPD. Subsequently, the abstract objectives of the CRPD cannot be achieved. If lawmakers do not acknowledge the existence of the rights of people with disabilities, how can people with disabilities enjoy equality before the law? 48 Moreover, Article 8 of the CRPD requires that states raise awareness of the needs of and barriers facing persons with disabilities in society. A decisive outcome in Paulley's case and reasoned and detailed obiter that could have been made public would have gone far in achieving this.

\section{The continuing problem with reasonable adjustment}

In the Court of Appeal case, Lewison LJ considered the Human Rights Equality Commission guidelines on when an adjustment is considered reasonable. These focus primarily on costs and the disruption resulting from adjustments made to accommodate people with disabilities. He made the distinction between a 'reasonable' and an 'effective' adjustment by referencing Slade LJ in the Employment Appeal Tribunal case, Lancaster v

38 G Quinn, 'Rethinking Personhood: New Directions in Legal Capacity Law and Policy, or How to Put the "Shift" back into "Paradigm Shift" (University of British Columbia, Vancouver 2011) 17.

39 Ibid.

40 Ibid.

41 Pearson, 'A Comparative Study' (n 36) 2.

42 Ibid 21.

43 Ibid and Optional Protocol (2006) Article 9.

44 Ibid Article 5.

45 Ibid Article 24.

46 Ibid Article 25.

47 Ibid Article 29.

48 Ibid Article 12 
TBWA Manchester: 49 'an adjustment which gives a Claimant "a chance" to achieve a desired objective does not necessarily make the adjustment reasonable'. ${ }^{0}$

However, he argued that cost considerations superseded the need for reasonable adjustments to be effective. ${ }^{51}$ This, then, begs the question whether 'reasonable adjustments' are really anything more than nominal concepts which pay lip service to the requirements of the legislature, to be seen to be doing something to make changes to secure social participation. This economic focus is incongruous with the perspective shift of the CRPD towards a rights-based focus. ${ }^{52}$ It also appears in the CRPD at Article 2 and would be better to be replaced with 'assurance of rightful access'. ${ }^{53}$ This reiterates the rights focus and removes the notion that disabled people should be mindful of 'not making unfair demands' and that these should be 'moderate in price' and 'average'. 54

Whilst the Supreme Court was not concerned with making changes to the concept of reasonable adjustment in this case, it is possible that had their lordships adopted a rightsbased focus to considering the existing PCP, they might have been able to highlight costconscious but effective solutions which could have opened the door for a re-evaluation of the concept of reasonable adjustment and the ways of funding increased accessibility. An example of a cost-conscious but effective adjustment would be a way to carry folded wheelchairs or buggies securely, if needed. This was considered by Arden LJ in obiter. However, it was already assumed to be costly and that expense would have to be taken into account. ${ }^{55}$ This again places economics above rights. Moreover, Arden LJ observed that First Group had not considered whether such improvements could be made, despite the need to regularly review adjustments. Interestingly, comment was made that if $\mathrm{Mr}$ Paulley had been able to show that on his route there were always buggies in the wheelchair space, so that he was effectively deprived of the opportunity of travelling by bus, which Parliament had intended to protect, the outcome of the case may have been different. ${ }^{56}$ This suggests that there is burden on the disabled person to show disadvantage, rather than for a company to show real evidence of anticipating the need for a particular adjustment despite the aims of s 20 of the Equality Act 2010. This is a further indication that the economic perspective supersedes the human rights perspective in practice.

In the Supreme Court ruling, the judgments of Lady Hale ${ }^{57}$ and Lord Clarke ${ }^{58}$ laid out that the purpose of reasonable adjustments is to overcome specific disadvantage experienced by persons with disabilities, not those with buggies. Lord Kerr highlighted that the recorder's original judgment meant that parents would not be forced off the bus if their buggy could be folded down. However, it is important to recognise that parents can choose whether or not to fold their buggy, or purchase one which can be folded down if no space is available. If they choose not to purchase a folding buggy then it is this

49 Lancaster $v$ TBWA Manchester (2011) UKEAT/0460/10/DA, [46]

50 First Group plc v Paulley [2014] COA EWCA Civ 1573, [44].

51 Ibid [45].

52 Pearson, 'What's Worth ...' (n 35).

53 Ibid.

54 Ibid.

55 First Group plc v Paulley [2014] COA EWCA Civ 1573, [82].

56 Ibid [83].

57 LJ Hale at 32, [94].

58 LJ Kerr at 52, [157]. 
choice that means they would have to leave the bus, not an order from the court. ${ }^{59}$ These judgments were not made on emotional grounds. For example, there is no talk of unaccompanied children being scattered in the hedgerows as implied by Lord Neuberger. ${ }^{60}$ Also, the discussion of the point of reasonable adjustments and their aims negated the issues of hierarchies of difficulties, which the other judgments failed to do. Emphasising that the purpose of reasonable adjustments is to overcome the disadvantage experienced by persons with disabilities when interacting with social structures, such as buses, and highlighting that there will be circumstances under which wheelchair users would not have the priority over the space (when it is already occupied by a wheelchair user or a person with another form of mobility equipment), then the distinction is rightly made that it would be reasonable for the wheelchair user to wait. ${ }^{61}$ This is positive because it acknowledges that persons with disabilities are not unreasonable and simply want fair access, while also understanding other people's issues and points of view.

\section{Common decency and virtue ethics: or rights v social niceties}

Both the Court of Appeal and Supreme Court judgments argued that moving from a wheelchair space to permit a wheelchair user to access the bus was a matter of 'common' decency ${ }^{62}$ and 'courtesy'. ${ }^{63}$ Relying on public decency to enable persons with disabilities to access public services and participate in society embodies a right by charity approach, which is both paternalistic and dangerous, as it disempowers one group to another. In Book II of The Nicomachean Ethics, Aristotle stated that: 'legislators make citizens good by forming habits in them, and this is the wish of every legislator and those who do not effect it miss their mark, and it is in this that a good constitution differs from a bad one'. ${ }^{64}$

In the case of Mr Paulley, the Supreme Court and other judges appear to be attempting to form 'good habits' in citizens by modelling them in court judgments, but the lack of enforcement in their own decisions (such as deciding that bus companies have to take more decisive action to remedy difficulties) means that these virtue ethics are not put into practice and can be said to have resulted in a bad constitution. Additionally, this highlights a discrepancy with virtue ethics and its lack of deontology or normative power, because it does not tell people how to act, or assist them in practical situations. It only tells them to think about what a 'good person' would do. This is also problematic because it assumes that all virtues and values are universal and of the same importance to everybody.

Morris explores the impact and development of a charity-based approach to disability and the way that misrepresentations of disability can be used to generate charity revenue which undermines the concept of people with disabilities as autonomous beings. ${ }^{65}$ Morris argues that a possible antidote to these negative representations of disability is the development and promotion of a disability culture that would present people with disabilities with accurate, self-made representations which would give confidence and

59 LJ Kerr at 43, [131] and 44, [133].

60 LJ Neuberger at 26, [81].

61 LJ Hale at 35, [105].

62 LJ Lewison, Court of Appeal [1].

63 LJ Sumption at 30, [88].

64 Aristotle, The Nicomachean Ethics, W D Ross (trans) (Oxford University Press 1998).

65 J Morris, Pride against Prejudice: Transforming Attitudes to Disability (Women's Press 1991) 73. 
pride in difference and acknowledge that the experiences of people with disabilities are valuable and important. ${ }^{66}$

Campbell offers a succinct description of the general movement in the charitable representation of disability from the 1950 s to the 1980 s. $^{67}$ Between the 1950 s and the 1970 s she categorises the approach to charity and disability as 'fundraising garden parties' where people talked about 'poor unfortunates' and 'incurables' who could be 'cared for'. 68 The majority of emphasis was not on representations of people with disabilities themselves, but on the focus of those more fortunate in doing 'selfless deeds'. ${ }^{69}$ There were elegant images of able-bodied people consuming tea and cakes from fine china, but no people with disabilities. ${ }^{70}$ Campbell argues that people with disabilities were 'acted upon' rather than consulted. ${ }^{71}$ Campbell moves on to discuss the 1980 s which she labels 'the decade of the courageous and exceptional' which began to question institutionalisation, and constructed another image of people with disabilities as 'an example to everyone', where people achieved major feats of courage and bravery or had special skills in undertaking everyday tasks. ${ }^{72}$ In 1990, she argues that people were encouraged to 'look at the ability not the disability'. ${ }^{73}$ Campbell argued that after consultation with people with disabilities, organisations and charities were concentrating on recognition of contributions to society rather than on the impairment, although Campbell argues that this ignores the impact of the impairment and does not give any status to people with disabilities. ${ }^{74}$ This new image was simply another way of asking society to recognise normality, rather than providing positive images of disability and addressing barriers. ${ }^{75}$

Both Morris and Campbell offer interesting insights into the discussion of the relationship between rights and charity for people with disabilities. Whilst both advance a rights-based perspective over the benevolent benefactor approach of charity, both indicate difficulties that would appear to underpin modern and legislative approaches to this dichotomy. For example, Morris continues the trope of reasonableness in her calls for people with disabilities to be able to enjoy 'a reasonable quality of life'. ${ }^{76}$ The use of the word 'reasonable' here perpetuates and, in some senses, legitimates the low expectations of people with disabilities about their quality of life. It also lowers the expectation of those instrumentally involved in the expenditure on and legislation for the rights of people with disabilities to access society and the services that it entails. Both Morris and Campbell emphasise the difficulties with, and the danger of, continuing a separatist approach in terms of disability and the wider society. In terms of the legislative framework, it may be possible to argue that, by parcelling the rights of people with disabilities into specific pieces of legislation, thus building a patchwork of

66 Ibid 75 .

67 J Campbell, 'Developing our Image: Who's in Control?', in Disability Studies Leeds, paper presented at 'Capin-Hand' Conference (February 1990) <http://disability-studies.leeds.ac.uk/files/library/CampbellDEVELOPING-OUR-IMAGE.pdf>.

68 Ibid.

69 Ibid.

70 Ibid.

71 Ibid.

72 Ibid.

73 Ibid.

74 Ibid.

75 Ibid.

76 Morris (n 65) 16, 72, 78 and 92. 
documents that are superimposed into existing legislation, it is arguable that their mere existence is addressing the problem, regardless of how effective or ineffective their implementation and use may be. This ghettoisation within the legislative framework might halt the effectiveness as much as it could help it. Campbell also exhibits elements of this separation in her discussion of changes to charity approaches because she argues that, whilst people with disabilities should be recognised as people who can achieve things, she also argues that this recognition of achievement should not eclipse recognition of the impairment and the importance of the impairment to the person. However, continually arguing that disability and impairment should have a status of their own is potentially alienating to people with disabilities who do not identify with this sense of feeling, as explored by Shakespeare. ${ }^{77}$ Therefore, it is possible to argue that both authors illustrate that a way to overcome existing weaknesses in both the framework and its implementation is to recognise, defend and value the right to choose, either to live a great life instead of a reasonable one, or to be seen as a disabled person or a person with a disability.

\section{Signs, stereotypes and spaces}

Lord Neuberger referred to the presence of a 'wheelchair sign' and a note requesting passengers to give up the space to a wheelchair user, when required, as a means of demonstrating that First Group had exceeded its requirements under the accessibility regulations by placing the note in addition to the symbolic sign. However, simply assuming that the use of the wheelchair sign will ensure accessibility for people with disabilities is naive at best and tokenistic at worst. Several authors have highlighted issues with the use of pictorial symbols as a means of securing disability access. For example, Ben-Moshe and Powell ${ }^{78}$ evaluate the current movement to reconceptualise the international symbol for access that is currently a person in a white wheelchair on a blue background, reinforcing the sense of a hierarchy of disability, with wheelchair use representing disability as a whole. Wilkins argues that this symbol should be abolished and replaced with a large letter A. 'A' stands for many things: 'A for Accessible. A for Accommodating. A for All ... The "A" doesn't just focus on architectural access but on attitudinal access. ${ }^{79}$ Moshe and Powell view this suggestion as positive because it focuses on the role of the designers rather than the people who are wrongly excluded. However, they also argue that the use of the letter ' $\mathrm{A}$ ' may not be practicable because different letters have different meanings in different languages. ${ }^{80}$ They suggest the universal access symbol used in the Apple operating system as a potentially universal replacement. ${ }^{81}$ However, unlike Wilkins' suggestion, which encompasses elements of the social model, prompting people to consider both the need for accessibility and their attitudes, the suggested Apple symbol ignores what is intrinsically different about the experience of people with disabilities compared to those without. Reeve criticises the traditional symbol of access because it:

77 Shakespeare (n 29) 55-6.

78 L Ben-Moshe and J J W Powell, 'Signs of our 'Times? Revis(it)ing the International Symbol of Access' (2007) 22(5) Disability and Society 489, 501.

79 D Wilkens (2004) 'Thoughts on the International Symbol of Access' 15(3) Access Press Online, in Ben-Moshe and Powell (n 78).

80 Ibid 502.

81 Ibid. 
. . . serves to legitimate some forms of bodily differences over others. People with hidden impairments who do not match the stereotypical disabled person who is a wheelchair user or older person can find themselves challenged when they use facilities ... consequently someone may decide to adopt a physical marker of disability to use these facilities. ${ }^{82}$

She argues that this can result in an emotional cost of having to publicly identify as being disabled. However, it is arguable that the 'A' approach suggested by Wilkins, and critiqued by Ben-Moshe and Powell as not providing linguistic clarity in all languages, also fails to provide clarity of experience, much in the same way that the existing symbol does, according to Reeve. ' $\mathrm{A}$ ' as accommodating for all, equally means accommodating to parents with buggies, to people who wish to move pianos by bus, or even to place their feet on the seat for a rest. It fails to conceptualise and respect the totality of the experience of people with disabilities: failure to access the bus could lead to failure to keep an appointment, which could lead to ill health, unemployment, personal care difficulties or any other number of consequences which could be continued over days, months and years if a line in the sand were not drawn and the right to access guarded both by the courts and society.

A further difficulty with the traditional symbol is that it does not mean anything. Deconstructed by the eye it is a dot over a right angle with a semi-circle underneath. It does not represent a wheelchair user, or a person with any impairment or disability, or even a person at all. It has become a sort of social conscience anaesthetic decoration, but it has proved so effective that the social conscience element has been completely desensitised and it is now seen as something which signals convenience in general rather than necessity for members of a social group to be able to access their rights. Therefore, there is an argument for modification, but any such modification must communicate the three-dimensional experience of disability and not solely focus on impairment, but rather the consequence of the interaction of the impairment with a society lacking awareness of the impact in using social structures which thus creates disability.

Conversely, Lady Hale recognised that people with disabilities are as likely as those without disabilities to require access to public transport to enable them to get to work. She highlighted that lack of access is one of the principal reasons that people with disabilities can find difficulty in accessing employment. ${ }^{83}$ This statement is positive because it challenges images of people with disabilities as non-wage earners who can, and should, wait to access their rights because they have nothing important to do; it emphasises that society plays a specific role in the issues that people with disabilities face and the construction of stereotypes.

In the Court of Appeal case, Lewison LJ discussed the provision in the regulations that tip-up seats may be added to the wheelchair space along with a sign asking 'Please give up this space for a wheelchair user.' 84 This could lead to negative comment from other people, making people with disabilities feel conspicuous and inconvenient rather than dignified members of their society. 'Please' is indicative of an attitude that people with disabilities must negotiate for the right to use the bus rather than possessing the right as a member of society. However, Underhill LJ argued that:

82 D Reeve, 'Negotiating Psycho-emotional Dimensions of Disability and their Influence on Identity Constructions' [2002] 17(5) Disability and Society 493-508; D Reeve, 'Part of the Problem or Part of the Solution? How Far do "Reasonable Adjustments" Guarantee "Inclusive Access for Disabled Customers"?' in K Soldatic et al (eds), Disability, Spaces and Places of Policy Exclusion (Routledge 2014) 111.

83 LJ Hale at 31, [93].

84 First Group plo v Paulley [2014] COA EWCA Civ 1573, [11]. 
In this context, the word 'request' does not mean simply asking a favour: the driver is conveying to the non-wheelchair user that they ought to move because the space is meant for wheelchair users who have priority. ${ }^{85}$

However, he acknowledged that with no power to compel passengers to leave the space there was little that could be done to overcome the difficulties highlighted by Lewison LJ (at para 50), ${ }^{86}$ therefore it is arguable that people with disabilities have to negotiate for their rights without real support. Lewison LJ also highlighted the Public Service Vehicle Accessibility Regulations 2000, which require that buses be fitted with not less than one wheelchair space of specified dimensions (defined in either para 3 or 4) on the lower deck of the bus. ${ }^{87}$ The bus in the Paulley case complied with para $4 .{ }^{88}$ Reference was made to the diagram in Part II of the schedule to illustrate the dimensions of the chair to be carried. This clearly shows a manual wheelchair. This is potentially problematic as not all wheelchair users are able to use manual wheelchairs independently, which means that electric wheelchair users may not have equal access to public transportation that other wheelchair users have. Additionally, it may be argued that the lack of representation of the diversity of wheelchair use presents wheelchair users as an amorphous group and does not understand the desire and need for independence and the link with self-esteem. Geças argues that self-esteem is sub-divided into two dimensions - competence and worth. ${ }^{89}$ Burke and Cast state that 'competence' refers to how capable and useful people believe themselves to be, while 'worth' is the perception that people have of their value in relation to others. ${ }^{90}$ Legislation has the power to both augment and diminish selfesteem: clauses providing adjustment to the built environment to enable people with disabilities to function independently, or to exercise their right to personhood, increase their sense of competence and, consequently, self-esteem. This is dependent on a sense of independence, control over the built environment and a positive self-identity.

A further example of attempts to control the identity of wheelchair users is the refusal under the 2000 regulations to permit wheelchair users (who wish to and are able to do so) to transfer to a seat and fold their wheelchairs. This is particularly damaging because it, in a sense, ties the wheelchair user to their chair and leads them and their ability to participate in society to be defined by it. It also deprives a wheelchair user of the sense of agency and choice that is available to other travellers. Moreover, it is interesting that Lewison LJ was unwilling to describe a baby sleeping in a buggy as a cumbersome and bulky item, and that no comment was made about wheelchair users being unable to transfer from their chair and store it in another part of the bus (due to the regulations). ${ }^{91}$ This shows both disrespect and inherent misunderstanding of the point and value of a wheelchair to the person using it. A wheelchair is not simply an object; for many it is a key element of their independence and agency, which enables them to participate in society, and therefore the same respect for it should be shown as to the buggy. This would help everyone in society to see its value and change the perspective of it as a cumbersome item, separate from the user, that society must accommodate at the inconvenience of others, which was a trope of both cases.

85 Ibid [66].

86 Ibid 10.

87 Public Service Vehicle Regulations 2000, Schedule 1, Part 2, Diagram A.

88 Ibid.

89 V Geças and M L Schwalbe, 'Beyond the Looking-glass Self: Social Structure and Efficacy-Based Self-Esteem' [1983] Social Psychology Quarterly 46, 77-88.

90 P J Burke and A D Cast, 'A Theory of Self-Esteem’ [2002] 80(3) Social Forces 1042.

91 LJ Lewison, Court of Appeal [16], [48]. 
Another difficult linguistic element appears in Lord Neuberger's judgment which talks about people without disabilities 'allowing' persons with disabilities to access the wheelchair space. This is indicative of unequal power relationships between persons with disabilities and those without because the word 'allow' conjures up images of a benevolent and enlightened society bestowing the right of access on persons with disabilities, rather than them being entitled to access things through being members of a community. An additional issue with Lord Neuberger's judgment was the emotive language used regarding competitions of need. There is a strange comparison between a new-born baby and a kebab ${ }^{22}$ to illustrate a point about antisocial behaviour in the Public Service Vehicles (Conduct of Drivers, Inspectors, Conductors and Passengers) Regulations 1990, s 6 (1)(b). This had the unfortunate effect of bringing to mind Jonathan Swift's pamphlet 'A Modest Proposal', not only through collocating a baby with an edible item, but also the undertone of some of Lord Neuberger's argument that persons with disabilities would be so unreasonable in claiming their rights that they would see newborns (with no mention of their mothers incidentally) littering the highways, much as the land-owner in Swift's imagination would see them grace his table. ${ }^{93}$

Lastly, both Lord Neuberger and the Court of Appeal judges described the need for equality legislation to consider 'the realities of life and interests of others' 94 which seems to be a misunderstanding of the point of equality legislation that was instituted precisely to overcome those difficulties, particularly for persons with disabilities, as highlighted by Lady Hale and Lord Kerr, which puts persons with disabilities directly at a disadvantage based on these readings.

\section{The Supreme Court ruling: a case of the emperor's new clothes?}

The rulings of Lord Neuberger, Lord Clarke and Lord Sumption present some difficulties and highlight continuing issues with reasonable adjustment similar to those discussed above: that what is considered reasonable is often decided based on the parameters and experiences of people without disabilities. This is particularly evident in para 51 of Lord Neuberger's judgment in which he argues that a parent with a baby in a buggy will have good or understandable reasons for refusing to move and that any challenges to these reasons may result in either confrontation or violence. It is arguable that, in making these arguments, Lord Neuberger is on the verge of accommodating this difficult behaviour, rather than challenging it and demonstrating an understanding of the purpose and need for reasonable adjustments. Moreover, at para 52, his arguments fail to see the point of view of wheelchair users or any person with a disability requiring the use of that space. This could amount to an example of judicially sanctioned indirect emotional disablism, as identified by Reeve. This happens when people who do not have to use reasonable adjustments fail to see the negative psychological effects that can occur, either when these reasonable adjustments fail to fulfil the purpose of overcoming disadvantage, or their use becomes embarrassing. This could become the case, particularly considering Lord Neuberger's suggestion (at para 53), and the measure ultimately decided on as a compromise between throwing people off the bus and doing nothing, namely to stop the bus for a time. It was his hope that doing so would 'pressurise' anybody refusing to move to change their mind. However, it is difficult to see how likely this would be to avoid

92 LJ Neuberger 19, [54].

93 Secret-satire-society.org, A Modest Proposal and Other Short Pieces including a Tale of a Tub by Jonathan Swift (Pennsylvania State University 2008) <www.secret-satire-society.org/wp-content/uploads/2015/11/ Jonathan-Swift-A-Modest-Proposal.pdf>.

94 LJ Neuberger at 25, [72]. 
confrontation, and it is also arguable that it would place persons with disabilities in a particularly vulnerable position because, if the rest of the passengers riding the bus became frustrated with being held up, they may channel this towards the person with the disability, rather than the person refusing to move. This could lead to persons with disabilities having to deal with several agitated passengers rather than a single difficult passenger refusing to move. Recall that Lord Neuberger had already made the argument that a wheelchair user's request for reasonable adjustments also had to be made in the context of not inconveniencing others or causing delay. ${ }^{95}$ This reasoning is flawed because it fails to understand that persons with disabilities can also experience these issues and they are not solely the preserve of the able-bodied; it also demonstrate his awareness that these factors may come into play in decision-making in terms of courses of action. It is difficult to see how this can qualify as a less aggressive policy.

Lady Hale and Lord Toulson recognised that the likelihood of confrontation is reduced if people understand rules clearly. Additionally, they argue that people who are likely to be so intransigent as to challenge this clarity publicly will be in the minority. If this were the case, a firm ruling would hopefully set new grounds of understanding for society at large and, as such, difficult behaviour would not be tolerated and would potentially be challenged. ${ }^{96}$ This contextualises the other lawlords' fear of potential confrontation and the decision to avoid it, whilst also avoiding the issues. Similarly, the judgments of Lady Hale and Lord Kerr remove the unnecessary discussion about the need for the driver to make an assessment as to whose need for the space is greater because they centre their discussions around disability rather than impairment. ${ }^{97}$ As non-disabled parents with buggies do not encounter disability unless their child is disabled (in which case they would be entitled to use the space), then clarity is provided. However, it would have been refreshing, and perhaps more useful, for both Lady Hale and Lord Toulson to speak about disability, rather than wheelchair use exclusively, in their judgments.

Additionally, regarding Lord Neuberger's supposed solution to the problem, there is no discussion of the need for the bus companies to support the driver in his or her actions of stopping the bus if this would result in regular delays or difficulties in running the route as a result. ${ }^{98}$ Indeed, his references to this course of action specifically mention when the bus is running ahead of schedule, thus negating the possibility that delays could be caused in real life. Moreover, by arguing that the driver may form a view or that the driver may conclude that a person without a disability has sufficient grounds to decide not to move has the potential to make such a suggestion even more unworkable, particularly if the driver were to do so quickly to avoid the possibility of delays and to please the company's management if the previously mentioned support is not given. This would mean that persons with disabilities are perhaps doubly disadvantaged by both the individual and corporate procedures. In failing to consider such issues, it is arguable that Lord Neuberger is demonstrating that he is far removed from the realities of daily bus use and the pressure on both service providers and users, but also that he has failed to understand that the frequency with which this issue is likely to arise means that it would probably be unworkable.

95 LJ Neuberger at 19, [53].

96 LJ Hale at 35-6, [106].

97 LJ Toulson at 28, [82].

98 LJ Neuberger at 23, [67]. 
However, there is social and legal precedence to suggest that the law has a role in modelling social behaviour. The value of social modelling of this nature is demonstrated by responses to the 2007 smoking ban in England. There was evidence from two longitudinal studies conducted between 2009 and 2010 that, as a result of the ban, smokers questioned had 'reduced consumption largely because of the inconvenience of going outdoors to smoke, but also because of a perception that their greater visibility as a smoker attracted public disapproval'. ${ }^{99}$ This finding indicates that public disapproval and government engagement with previously accepted behaviours can motivate social change that supports the potential impact of engagement by bus drivers in challenging passengers who refuse to move from wheelchair spaces. For example, Roscoe Pound cites that, although there is a relationship between law and ethics, neither can be achieved by solely relying on the other. ${ }^{100} \mathrm{He}$ also states that effective legal order is considered by including three separate factors to ensure a sound legal order:

- that justice is the ideal relation between people;

- that morals are the ideal development of the individual character; and

- that security must be assured. ${ }^{102}$

It is necessary to keep all three of these elements in balance to ensure aims in practice. ${ }^{102}$ Therefore, in relation to disability law, relying on a sense of ethics, as shown in the judgments discussed in this article, will not achieve the outcome of security for people with disabilities. To do that, there needs to be consideration of how the law can provide this security. Other elements that need to be considered are Pound's assertion that law can only deal with external matters and behaviour and not internal ones, thus effective machinery and efficient outside agencies are required to evoke the law and thus change behaviour where necessary. ${ }^{103} \mathrm{He}$ calls this 'educative legislation', which provides a means for governments to promote ideals rather than offering means for litigants to enforce their rights. ${ }^{104}$ It is arguable that disability-specific legislation in the UK fulfils this role, as well as providing a means for redress by setting anticipatory adjustment duties. However, the implementation of this legislation could be improved, as demonstrated in the Paulley cases. Pound recognises the importance of incentives which could be used in practice to secure more complete implementation of legislation in the UK and remove economic or social decision-making around access provisions. ${ }^{105} \mathrm{~A}$ further example of growing public momentum to accept change around access to wheelchair spaces on public transport was indicated in February 2016 with Transport for London's Buggy Summit which served as a forum for parents and passengers with disabilities, bus companies and buggy manufacturers to come together and discuss problems in order to work towards solutions. ${ }^{106}$ Therefore, it is arguable that, if the Supreme Court were to

99 L Bauld, The Impact of Smoke Free Legislation in England: Evidence Review (University of Bath 2011) <www.gov.uk/government/uploads/system/uploads/attachment_data/file/216319/dh_124959.pdf>.

100 R Pound, 'Law and Morals: Jurisprudence and Ethics' [1945] 23(3) North Carolina Law Review 185-222, 222. 101 Ibid.

102 Ibid.

103 R Pound, ‘The Limits of Effective Legal Action' [1917] 3(1) American Bar Association Journal 69-70.

104 Ibid 61.

105 Ibid 59.

106 Transport for London 'TfL Hosts UK's First Ever Buggy Summit' (18 February 2016) <https://tfl.gov.uk/info-for/media/press-releases/2016/february/-tfl-hosts-uk-s-first-ever-buggy-summ>. 
consider some of the arguments outlined in this article and to harness the potential and will of the public, a solution that acknowledges the rights of everyone could be found.

Additionally, there may be merit in considering the role of the public sector equality duty in relation to this case. Whilst private bus companies do not fall under the definition of public authorities and are outside the public sector unless they are carrying out a government-funded function, ${ }^{107}$ which was not the case with First Group plc, it is arguable that they perform a public function by moving the public around. As such, they offer the perfect 'space' due to regularity of contact and competing arguments to:

- eliminate unlawful discrimination, harassment and victimisation and other conduct that is prohibited by the Act;

- advance equality of opportunity between people who share a characteristic and those who do not; and

- foster good relations between people who share a characteristic and those who do not. ${ }^{108}$

Whilst writers such as Hepple have criticised the weakness of 'due regard' in the duty and a 'tick-box approach', ${ }^{109}$ it is arguable that if bus companies were compelled to defend the right of wheelchair users to access the service and to enter into negotiations with other passengers to find ways around conflicts of need, it would animate the legislation and give it the 'teeth' needed to tackle daily inequality and model a change in attitude towards social acceptance of exclusion.

\section{Conclusion}

In as much as the Supreme Court ruling was hailed a success by Mr Paulley and his legal representatives, ${ }^{110}$ the decision appears to represent a lost opportunity to send a signal that the rights of persons with disabilities and the ability to exercise these rights is nonnegotiable and that, in some cases, different treatment and potential inconvenience for people without disabilities will be needed to ensure substantive equality in practice. More worryingly still, the rhetoric in some of the judgments demonstrates that there is a disparity between perceived difficulties facing persons with disabilities and the reality. The presence of such disparity at the highest legal level suggests that more work is needed to change attitudes and practices. Only weeks after the ruling, there were more reports of persons with disabilities being unable to access public transport due to spaces being occupied by buggies, ${ }^{111}$ thus demonstrating that no clarity has been delivered.

107 Freedom of Information Act 2000, s 4(4).

108 Equality Act 2010, s 149.

109 B Hepple, 'The New Single Equality Act in Britain' [2010] Equal Rights Review 11-24, 16.

110 Disability Rights UK, 'First Group plc v Paulley: Supreme Court Upholds Doug Paulley’s Case against Firstgroup plc to a Limited Degree' (nd) < https://www.disabilityrightsuk.org/firstgroup-plc-v-paulley>.

111 ITV, 'Pushchair User Refuses Wheelchair User Access to the Bus: Outside Supreme Court' ITV News (18 January 2017) <www.youtube.com/watch?v=UDsuSTZcO3Y>. 
